\title{
The interaction between clothing and air weapon pellets
}

Graham Wightman, K. Wark and J. Thomson

This is the accepted manuscript (C) 2014, Elsevier

Licensed under the Creative Commons Attribution-NonCommercialNoDerivatives 4.0 International

http://creativecommons.org/licenses/by-nc-nd/4.0/

(cc) BY-NC-ND

The published article is available from doi: 10.1016/j.forsciint.2014.10.039 


\title{
The interaction between clothing and air weapon pellets
}

G.Wightman ${ }^{\mathrm{a}}$, K. Wark, J Thomson

a (Corresponding Author)

School of Science Engineering and Technology,

Abertay University,

Bell Street,

Dundee,

DD1 1HG,

Scotland.

g.wightman@abertay.ac.uk

Telephone: +44 1382308659

\section{Highlights}

- The effect of clothing on air weapon pellet penetration into ballistic gel has been examined.

- Damage to the clothing depends on pellet shape and fabric weave.

- Penetration depends: on range, pellet shape, the fabric weave, and how the clothing is in contact with the gel.

- With loosely draped clothing at 20 yards range few pellets penetrated the gel.

- Estimates suggest that these pellets stop in 75 microseconds, requiring a force of $1700 \mathrm{~N}$.

\begin{abstract}
Comparatively few studies have been carried out on air weapon injuries yet there are significant number of injuries and fatalities caused by these low power weapons because of their availability and the public perception that because they need no licence they are assumed to be safe. In this study ballistic gel was tested by Bloom and rupture tests to check on consistency of production. Two series of tests were carried out firing into unclothed gel blocks and blocks loosely covered by different items of clothing to simulate attire (tee shirt, jeans, fleece, and jacket).
\end{abstract}


The damage to the clothing caused by different shaped pellets when fired at different ranges was examined. The apparent hole size was affected by the shape of pellet (round, pointed, flat and hollow point) and whether damage was predominantly caused by pushing yarn to one side or by laceration of the yarn through cutting or tearing.

The study also compared penetration into clothed gel and unclothed gel under identical conditions, and loose clothing greatly reduced penetration. With loose clothing at $9.1 \mathrm{~m}$ range clothing reduced penetration to $50-70 \%$ of the penetration of unclothed gel but at $18.3 \mathrm{~m}$ range only 7 out of 36 shots penetrated the gel. This cannot be accounted for by the energy loss at the longer range (3-7\% reduction from $9.1 \mathrm{~m}$ to $18.3 \mathrm{~m}$ range in unclothed gels) and it is suggested that impulse may have a role to play.

Shots that did not penetrate the gel were used to estimate the possible stopping time for the pellet (around 75 microseconds) and force $(1700 \mathrm{~N})$ or stress(100 MPa) required to bring the pellet to a halt.

Even with these low energy projectiles, cloth fibres were entrained in the gel showing the potential for penetration of the body and subsequent infection. 


\section{Introduction}

Whilst there have been a considerable number of studies related to firearms, there has been limited research into the wounding capability of air weapons. Most of these studies have been in medical journals and have reviewed fatalities or types of injuries sustained [1,2]. There has also been some interest of late in studying air weapons to better understand their wounding potential. Wightman et al [3,4] have studied the interaction of air weapon pellets on different materials embedded in ballistic gel (bone, heart, lung and liver). Meng et al [5] have studied the effect of ambient temperature on air rifle and found an increase of muzzle energy density (muzzle kinetic energy divided by pellet cross sectional area) from 65 to $81 \mathrm{~J} \mathrm{~cm}^{-2}$ (a $24 \%$ increase) as temperature rose from 15 to $28^{\circ} \mathrm{C}$ (a $4.5 \%$ increase in absolute temperature). A spring piston air pistol increased muzzle energy by $3 \%$ over the same temperature range. The study also investigated the variation of muzzle energy with the number of pump strokes and found a quadratic relationship fitted the data. There has also been concern over the legal status of air weapons as in many countries they can be owned without restriction. Bruce-Chwatt [6] used a case study of an air weapon incident to review legislation in the UK, and Ogunc et al [7] have reviewed legislation in 18 countries. Ogunc [7] also reviewed 1414 cases of air gun injuries reported in the literature and analysed the anatomical distribution with $30 \%$ eye injuries, $23 \%$ lower limbs, and $16 \%$ head injuries representing the main sites.

Clothing can have an impact on projectile penetration and the present study examines the effect of clothing on air weapon damage. Body armour relies on this effect and Agrawal [8] notes that the first recorded ballistic armour consisted of 30 folds of cotton developed in Korea in the 1860's. The armour dissipates energy by deformation, cutting of yarn and transmission between layers. Nowadays other materials are used such as Kelvar, with ceramic materials sometimes included as well.

Whilst the development of body armour is well established for military applications, there is also an interest in the role of clothing for protection in criminal cases. Most studies appear to have been carried out to investigate the effect of clothing in attacks by knives and other sharp instruments. Whilst clothing will have some effect of firearms incidents it is unlikely to have a major impact on the outcome. In stabbing 
incidents on the other hand, the clothing may offer more protection than it does to a bullet, and the damage to the garment can provide forensic evidence as to the weapon used. Aming and Chiteree [9] examined stabbing through cotton or jean clothing into gelatine and measured the force applied by subjects which was typically $10 \mathrm{~N}$ for overarm (long range) and $50 \mathrm{~N}$ for underarm (close range) stabbing. The fibre damage could be differentiated according to the force used and the sharp or blunt end of the blade. Nolan et al [10] also studied the damage effect of knives under various applied forces by adapting a Hounsfield tensiometer for delivering the cut. The study reviewed the literature and found no quantitative data on the force required to penetrate everyday clothing and aimed to contribute to this area of knowledge. A foam and silicone rubber combination was used for the target and various items of clothing were examined: tee shirt, sweatshirt, rugby shirt, jacket, and combinations of layers as well as a slash hoodie (an anti-slash garment). Typically 10-20 $\mathrm{N}$ force was required compared with $10 \mathrm{~N}$ to penetrate the synthetic skin. There was some variation between blades but generally the tip penetrated before cutting occurred and each fabric had similar force requirements provided they had similar density of weave and strength of fibre. By contrast, the slash hoodie required 40-70 N. It was also observed that multiple layers required more force, although this was not simply additive. Johnson [11] discusses the mechanisms of damage to fabric and cites Heuse [12] for four mechanisms of penetration: pushing, cutting, shearing and tearing.

Venneman et al [13] studied the effect of clothing on conventional firearms using a 9 $\mathrm{mm}$ Parabellum fully jacketed projectile at $2 \mathrm{~m}$ range. This study assessed whether fibres could be drawn into the temporary cavity. The model employed was a $25 \mathrm{~cm}$ ballistic gelatine block with pig skin and covered with jeans or a cotton jersey; however, blue clothing material was used at the entry and red at the exit side of the block. As well as analysing the bullet track by the crack length they also recorded the firing with high speed video (6000 fps) and were able to view the temporary and permanent cavity. The track was cut into $1 \mathrm{~cm}$ lengths and these were liquified and centrigued and the fibres counted under the microscope. Profiles were generated on the fibres per cm length of track and there was a decline in number of blue fibres and an increase in number of red fibres along the profile, showing that negative pressure during the temporary cavity phase has drawn red fibres in from the exit hole. 
Kieser et al [14] adopted the technique of Wightman et al [3] and inserted bone into ballistic gel for firing. The authors claim there are 80,000 gunshot injuries annually in the USA and that $45 \%$ of these present with a bone fracture. Kieser embedded deer femur into $20 \%$ gel and fired $5.56 \times 45 \mathrm{~mm}$ rifle bullets at $970 \mathrm{~ms}^{-1}$ (average) into the gel. They found that the bone could be fractured even when the bullet did not impact the bone and only passed within $30 \mathrm{~mm}$ of the bone. This is attributed to the temporary cavity that is formed. To test this, a pressure sensor was placed in the gel, Doppler radar monitored entry and exit velocities, and a 40,000 fps camera recorded images of the firing. Two depths of embedding were used: 80 and $120 \mathrm{~mm}$. Firings were also conducted with single and double layers of jean cloth on the gel. Kieser found that yaw did not occur until $100 \mathrm{~mm}$ into the gel and as a consequence the narrower embedment of $80 \mathrm{~mm}$ meant that the maximum temporary cavitation occurred beyond the bone and as a consequence the energy transfer was approximately one third that in the thicker moulds (500J compared with $1500 \mathrm{~J}$ ). The presence of clothing had little effect on energy transfer. However, femur fracture occurred in cases where the gel was clothed but not in cases where the gel was unclothed (bullet passage within $10 \mathrm{~mm}$ or $20 \mathrm{~mm}$ of the bone). The temporary cavity volume varied with both gel size and the presence of clothing with average volume being 7 times greater in the thicker block than the thinner block (1640 compared with $235 \mathrm{~cm}^{-3}$ ) and doubled again with clothing (3710 compared with $1640 \mathrm{~cm}^{-3}$ ). Clothing also appeared to increase the temporary cavity volume in the narrower block. Multiple layers of clothing appeared to have little additional effect. It was concluded that clothing can increase the risk of indirect fracture and increase the temporary cavity size, and that the depth of gel or flesh also plays a part.

The findings of Kieser et al [14] at first appear contrary to the perceived wisdom of clothing reducing the effect of firearm injury [8], and are an important contribution to understanding firearm injuries. The reason may be the specific set of conditions they employed: the high kinetic energy of current weapons, indirect impact and the depth of flesh surrounding the bone. The study also only examined the effect on hard tissue and further work needs to be done to consider the application of these findings to soft vital organs. 
The present study aimed to consider the effect of clothing on low energy projectiles from air weapons. Here the interest is not on the temporary cavity formation (although Keiser's findings on the impact of gel depth will be important) but on whether the pellet may penetrate the body and how far penetration may occur in the presence of clothing. 


\section{Experimental}

\subsection{Gel preparation}

For the first series of tests the gel was prepared by a variation on the method proposed by Jussila [15]. $222 \mathrm{~g}$ of gelatine powder (Gelita technical gelatine $260 \mathrm{~g}$ Bloom value) were slowly added to $2 \mathrm{~L}$ warm water and $10 \mathrm{~mL}$ proprionic acid added as preservative. The solution was heated to $65^{\circ} \mathrm{C}$ for 10 minutes, poured and allowed to cool before storing at $2-4{ }^{\circ} \mathrm{C}$ for 24 hours.

For the second series a variant on the method proposed by Fackler was used [16] $100 \mathrm{~g}$ of gelatine granules (Fluka ballistic Type $1 \mathrm{gel}$ 250-290 g Bloom) were weighed out and added to a beaker containing $900 \mathrm{ml}$ of cold tap water. This solution was then stirred for 3 minutes in order to moisten the gelatine. The beaker was then placed in a water bath at $37.4^{\circ} \mathrm{C}$ with the water bat $\mathrm{h}$ lid in place and a timer started. At the 20, 40, 60 and 80 minute mark, the beaker was stirred for 3 minutes as overstirring can trap air in the mixture. At the 90 minute mark, 1 drop of cinnamon oil was added to the beaker as a preservative and stirred for a further 3 minutes. The gelatine was then tested for $\mathrm{pH}$ and transparency and once these tests were complete, the gelatine was poured into a rectangular mould and placed in a cold room at $2-4^{\circ} \mathrm{C}$ for 24 hours. After 24 hours, the gel atine was examined for clarity and air bubbles. If the gel was clear and showed no air bubbles, it was wrapped in cling film, labelled and stored in the cold room.

\subsection{Testing of gel properties}

Bloom value and rupture strength were examined using a TA.XT plus Texture Analyser by Stable Micro Systems with a $5 \mathrm{~kg}$ load cell, although an alternative probe was used with this load cell. This meant that load readings would not directly give the actual Bloom value of the gelatine due to the different cross sectional area of the probe, but they would provide a consistent comparison between blocks. The required probe was a $12.5 \mathrm{~mm}$ diameter cylinder probe $(\mathrm{P} / 0.5 \mathrm{R})$ with a contact area of 122.7 $\mathrm{mm}^{2}$. The probe that was used had a $36 \mathrm{~mm}$ diameter $(P 36 / R)$ with a contact area of $1018 \mathrm{~mm}^{2}$. Probe speed was $1 \mathrm{~mm} \mathrm{~s}^{-1}$ and the probe was pushed into the surface of the gelatine until $4 \mathrm{~g}$ of trigger force was obtained and at this point recording started. The probe then penetrated the gel to a depth of $4 \mathrm{~mm}$. 
For the rupture strength the probe pushed into the surface of the gelatine until $10 \mathrm{~g}$ of trigger pressure was applied. The probe then breaks the surface of the gelatine and continues to a depth of $8 \mathrm{~mm}$ at $0.5 \mathrm{~mm} \mathrm{~s}^{-1}$ and provides a graph of the force applied and indicates when rupture occurs.

When testing these properties, the probe was aligned to the centre of each gelatine block. The area used for testing was not the surface side that was being fired at.

\subsection{Firing arrangement}

To keep the results as reproducible as possible, a rifle bipod was used to support the barrel when firing and the gelatine blocks were placed on a table at a constant height. The rifle range was in an enclosed space and wind was not a factor that had to be considered. The temperature of the rifle range was also recorded to ensure this had no effect on the gelatine. The air rifles used were chronographed for the different pellet types examined. Table 1 gives these combinations. In series 1 four different pellet shapes were examined and series two concentrated on two pellet types as these are most common in use in the UK. Muzzle energy in series 1 was 14.0-14.7 J and in series 2 was 10.0-11.0 J

In the first series gelatine blocks were placed on the table inserted into a t-shirt or into a pair of jeans. The clothing was set up to resemble being worn by a person, making sure there were no folds in the clothing and that the clothing was in contact with the gelatine. When the clothing had been set up the four different pellet types where fired into each block from ranges of $9.14 \mathrm{~m}, 18.3 \mathrm{~m}$ and $27.4 \mathrm{~m}$. The clothing tested was: tee-shirt $40 \%$ polyester $60 \%$ cotton; tee-shirt $100 \%$ cotton; jeans $98 \%$ cotton $2 \%$ elastane; and jeans $75 \%$ cotton $23 \%$ polyester.

In the second series each item of clothing was placed loosely over the gelatine block but not pulled tightly around it. In this trial three different fabrics were chosen: a cotton tee shirt, a polyester fleece and a cotton jacket. Each block was shot three times, once from each range $(9.1,13.7$ and $18.3 \mathrm{~m})$. Six replicates were carried out on separate blocks.

\subsection{Analysis}


Gels and clothing were photographed with a macro lens and some clothing was examined on an opto-digital microscope (Olympus DSX100). Penetration measurements were made with a ruler to the tip of the pellet. 


\section{Results and Discussion}

\subsection{Physical properties of the gel}

As the gel properties are critical to the study, consistent conditions were employed throughout each series of tests. In the second series, the gel properties were monitored more effectively and the liquid gel was analysed for $\mathrm{pH}$ and transparency at two wavelengths as a quick check on consistency during production. Any that were outwith the supplier's specification were discarded. A number of set gels were also tested for physical consistency using a food-grade texture analyser and some of these results are shown in figures 1-3.

Figure 1 shows the Bloom-type test employed, although the probe had a larger diameter than normal. It does, however, show any inconsistency between gels. The Gelita gels showed a relatively small spread from 1110 to $1200 \mathrm{~g}(7.5 \%$ minimum to maximum) whereas the Fluka gels showed a $24 \%$ variation from 900 to $1200 \mathrm{~g}$. Fluka, however, give a range in the specification for the Bloom number of their gel from $250-290$, a $14 \%$ variation.

Figure 2 shows the rupture strength test for these gels with the alternative probe pressed into the gel. Again, the Gelita gels were more consistent with $6 \%$ spread compared with a $16 \%$ spread for the Fluka gels, and a higher applied force. Several of the Fluka gels also appear to show some onset of rupture with a slight intermittent drop in stress at $2200 \mathrm{~g}$. These tests confirm that there can be variability in the properties of formed gels and so for comparative purposes shootings took place into the same gel where possible. There are, however, practical limitations on the number of shots that can be fired into the same gel, and so gels produced in the same batch were used when using the same gel was not possible.

The effect of cinnamon oil as a preservative was investigated and two gels were produced with and without the preservative. These gels were sectioned into 4 smaller portions and were stored at $4^{\circ} \mathrm{C}$ and at $24^{\circ} \mathrm{C}$ and were observed over a two week period. The four sections without cinnamon oil at $4^{\circ} \mathrm{C}$ began to turn cloudy after 6 days. After 8 days these sections showed signs of decomposition; mould began to clearly form on the surface, the gelatine had started to liquefy and give off an odour. The four sections without cinnamon oil at $2^{\circ} \mathrm{C}$ showed no signs of change 
up until day 5 but at day 5 , the gelatine very quickly began to liquefy. The sections with cinnamon oil at $4^{\circ} \mathrm{C}$ after a 2 week period stil I displayed excellent clarity and no signs of mould growth These gels were tested for rupture strength at 1 day and 14 days, and as figure 3 shows there was little variation between the blocks and little change over 2 weeks of storage. After 14 days, the 4 sections of gelatine stored at $24{ }^{\circ} \mathrm{C}$ showed more variance in results and this may be due to the gelatine block losing firmness as decomposition and liquifaction set in. This may have increased the elasticity of the gelatine surface, allowing the probe to push further into the gelatine without actually rupturing the surface. The cinnamon oil did however prevent mould growth and the gel losing clarity but it did not fully stop decomposition.

Cinnamon oil did slow decomposition to a rate that meant the gelatine blocks could be stored in the cold room for up to a week until required for shooting.

In some cases, a white material seemed to be associated with the pellet (figure 4) and appeared to develop over time. It was considered whether this might be chemical reaction with the lead or the start of mould growth. Samples were taken for optical microscopy but appeared to melt under the microscope lighting. It was then speculated whether an emulsion of gel and air is forming or some other restructuring of the gel is occurring. The cause of this phenomenon is unidentified.

\subsection{The effect of clothing}

A pellet or bullet entering the body can cause injury by both the temporary cavity and the permanent cavity. Projectiles can also fragment, particularly when impacting on harder material such as bone (see, for example, the impact of air rifle pellets on bone [3]). A final source of injury can result from foreign material entering in the wound. From the physician's point of view the tissue damage, the presence of the projectile, and the introduction of microorganisms are the main initial threats. However, other extraneous material may also be entrained and in the present study, fibres from the clothing were observed to have been drawn into the gel. No pellet fragmentation occurred on impact with clothing.

Occasionally air weapons are loaded with the pellet backwards (i.e. skirt forward) to cause greater injury to vermin and a short series of tests was carried out firing pellets backward into gel without clothing. As may be expected when presenting the pellet 
skirt first penetration was poorer (see table 2) and a larger permanent cavity formed, but again no fragmentation was observed.

Impact with clothing could produce tumbling of the pellet with a consequent larger permanent cavity. However, most of the pellets appeared to keep a straight trajectory through the gelatine although in a few cases the pellet tumbled within the gelatine and this decreased its penetration depth.

In a number of cases, fibres were entrained with the pellet and were carried into the gel. Figure 5a shows one example of two fibres embedded in the soft lead of the pellet and carried with the pellet whilst figure $5 b$ shows fibres that have been carried into the gel but are no longer associated with the pellet. Having a density close to that of human tissue these fibres are less likely to be noticed in an x-ray examination but could still aggravate the healing process and need to be considered in wound treatment.

Depth of penetration by the pellet was reduced and was more variable in the gels covered by clothing. Table 3 shows the penetration in the first series of firings and pellet shape, clothing type, and (to a lesser extent) range have an effect on penetration. Table 4 gives results of the second series, and a difference can be observed between the two series. The first series is comparable with the study by Ogunc et al [7] but the second study produced contrary results. In this second phase of the study, a tee shirt reduced penetration to around $50 \%$, a fleece reduced penetration to around $65 \%$ and a denim jacket effectively stopped pellets at a $9.1 \mathrm{~m}$ range (table 4). In contrast, the first series and the study by Ogunc only found 3-15\% reduction in penetration due to clothing at 9-10 $\mathrm{m}$ range. Cail et al [8] have studied the effect of clothing on shotgun pellets and found that fabric afforded greater protection at increasing distance. Discussions with a local archery club suggested that loosely held cloth is used as protection in indoor ranges as the cloth can move and absorb energy whereas taut curtains surrounding the target can be penetrated by arrows. Although the air rifle was lower power in series $2(11 \mathrm{~J}$ compared with 14 $J)$ this reduction in power is probably unlikely to account for this difference. The difference between these two phases of the study (and Ogunc's study) could however be accounted for by how tightly the clothing was in contact with the gel. In phase 1 it was in contact but in phase 2 it was loosely draped. This difference could 
therefore be significant in evaluating air weapon incidents and requires a more detailed investigation in a future study.

As can be seen from tables 3 and 4,both the type of material and the pellet shape affect the penetration through clothing.

\subsection{Damage to the clothing}

There are various mechanisms by which clothing can be damaged and Heuse [12] suggests four that occur in stabbings: pushing, cutting, shearing and tearing. The damage depends on the fibre's mechanical strength, the tightness of the weave and the nature of the impact. Figure 6 shows the shape of the head of the pellet and figures 7 (series 1) and figure 8 (series 2) show the effect of different shaped pellets on different fabrics. The pointed pellet caused least damage to the tee shirt and the jeans and has predominantly pushed the fibres with some tearing, and cutting or shearing. The round pellet has created more damage to the fibres but again it has been able to push the fibres to help form a hole. The hollow point and flat pellets have caused more damage to the fabric leaving a residual hole and laceration of the yarn into individual fibre threads. There is a difference in weave between the two fabrics as well as yarn size even though they are both cotton or substantially cotton fibres, and the tee shirt is a knit or loop stitch compared with the warp and weft plain weave of the jeans. This is partly seen in the nature of the damage to the fabric where the jeans' fibres have effectively covered the entry hole.

Figure 8 compares the round superdome pellet with the flat hobby pellet and similar trends can be seen in the knit stitch tee shirt and the plain weave jacket (although the jacket also has two layers of fabric). The teeshirt has been damaged mainly by pushing and moving fibres to one side with limited evidence of cutting or shearing. Interestingly the flat pellet has also pushed rather than lacerated or torn the fibres. The fleece is a series of non-interlinked fibres and it had been expected that its fibrous nature might absorb the energy of the impact by deformation and give more protection but this was not the case, and this may be due to the reduced interdependency of the fibres when not twisted into yarn and woven. The flat pellet has produced a larger hole than the rounded pellet. The jacket has a similar weave 
to the jeans and behaved similarly to jeans and a combination of pushing and tearing/cutting/shearing has occurred.

\subsection{Non-penetration of the clothing.}

Other studies have investigated the missile energy necessary to penetrate skin [17] and it has been shown that an air-skin-gel boundary can behave differently from an air-gel-skin-gel boundary [4]. It is therefore of interest to consider cases where nonpenetration occurred. Figure 9 shows examples of firings where penetration did not occur, and the clothing prevented penetration of the gel, typically at $18.3 \mathrm{~m}$ range in the second series. In the tee shirt the pellet has produced a depression in the cloth by stretching the fibres with some evidence of tearing of yarn at the edge of the cup shape. Similarly the fibres of the fleece have been compressed into a cup shape and the fibres form a more dense mat at the base. The jacket weave has not formed a cup, possibly due to the higher tensile strength of the thicker yarn, but there is evidence of tearing of the fibres from the yarn. In previous studies with animal and bird skin placed in contact with ballistic gel it has been observed that the combination is stronger than when skin was embedded in the gel [4] and in unpublished work on building materials it has been found that when layers of wood or plasterboard are in contact with each other, air rifle pellet penetration is reduced compared with cases where an air gap existed between the layers. It is thought that there is mutual support between the layers to absorb the energy of impact. In the present study no shots were fired at clothing alone so it is not possible to compare the two cases.

However, there was evidence of damage within the gel behind the clothing as shown in figure $9 b$. The rupture tests (section 3.1, figure 2) suggest that quite a high force is needed to cause rupture of the gel and the pellet is unlikely to produce a comparable force. On the other hand, it is possible that the impulse (force $x$ time, which equals the change in momentum) may be quite high if the time is very short and this might explain the damage. The damage appears to have occurred to a centimetre or two within the gel and this would result in serious bruising within a human body even if penetration was prevented by clothing.

\subsection{Energy loss due to clothing}


A particular area of interest in this study was the energy loss due to the presence of clothing and table 4 shows the data from replicate firings in series 2 . The mean muzzle energy of the superdome pellet was $10.96 \mathrm{~J}$ and the Hobby pellet was 10.92 J. As can be seen, replicate firings were reasonably reproducible. As might be expected there are occasional outliers that have been highlighted and these are excluded from calculation of mean and standard deviation. As discussed previously, gels were prepared to the same method and shots at 9.1,13.7 and $18.3 \mathrm{~m}$ were into the same gel so if there was inconsistency in a gel this would be expected to repeat across the three ranges but this does not appear to be the case. Likewise, replicate chronograph tests were consistent. The likely cause therefore of these outliers is probably connected with the clothing: it may be that part of the clothing was in contact with the gel and supported by it; the fabric may be strengthened by a nearby seam; it is possible that impact caused the pellet to tumble and hence penetrate less; or it may be the tautness of the cloth as noted in section 3.2

Allowing for the variability, there are some noticeable trends. Firstly, the flat hobby pellet consistently penetrated $15-20 \%$ less than the more streamlined round superdome. Secondly, there is a reduction in penetration at greater range, although this is relatively small for unclothed gels $(12.68 \mathrm{~cm}$ at zero range (table 2$)$ to 11.87 $\mathrm{cm}$ and $11.17 \mathrm{~cm}$ at 9.1 and $18.3 \mathrm{~m}$ (table 4) for superdome and $10.65 \mathrm{~cm}$ to 9.30 $\mathrm{cm}$ and $9.05 \mathrm{~cm}$ for the hobby, or 5-15\% reduction), or for a teeshirt in contact with gel (less than $10 \%$ reduction going from 9.1 and $18.3 \mathrm{~m}$ range for all pellet types). Thirdly, there is a difference between the fabrics with the fleece and tee shirt providing least protection and the woven jacket and jeans most. Fourthly, at $18.3 \mathrm{~m}$ all three fabrics prevented penetration when loosely draped around the gel.

The two pellets (Superdome and Hobby) had similar muzzle velocities but the rounded pellet has a reduced drag coefficient and will penetrate further into the gel (the flat Hobby pellet typically penetrated $20 \%$ less at all three ranges for unclothed gel). A similar effect is seen in table 2 for pellets fired backwards at zero range where penetration was 35-45\% less than when fired normally. Wightman et al [3] found that pointed pellets penetrated around 10-15\% more than rounded pellets. Drag coefficient depends on a variety of factors and will depend on the flow regime but a flat surface has a much higher Cd value (drag cefficient) for the same cross 
sectional area (e.g. 1.28 compared with 0.295 [18]). However, if it were simply viscous drag (equation 1) on the pellets the restraining force on the rounded pellet would be half to a third that on the flat pellet at each velocity and a larger difference would be expected.

$$
\text { (1) } \quad F_{d}=c_{d} 1 / 2 \rho v^{2} A
$$

In practice the gel is a solid rather than a fluid and the gel structure has to rupture and be displaced to allow the pellet through (see for example, Jussila's evaluation of three model's of gel fracture [19]). Whilst shape does affect penetration and damage, the mechanism is therefore complex.

For unclothed gel there was a reduction in penetration from 9.1 to $18.3 \mathrm{~m}$ range of between 5 and 15\% depending on the pellet shape, and comparing table 2 and 4 the reduction was $6-13 \%$ going from zero to $10 \mathrm{~m}$ range. The superdome pellets show a consistent decline with range but the hobby pellet appears to give a similar penetration both at 9.1 and $13.7 \mathrm{~m}$ due to the variability in results. As pellets were fired into the same block of gel this is not simply due to variability in the gel, and the trend of $9.1 \mathrm{~m}$ appearing to result in lower penetration than $13.7 \mathrm{~m}$ can be seen in some individual blocks. However, the overall trend from zero range to $18.3 \mathrm{~m}$ is consistent. This variation could be due to imperfections in the pellet caused during storage and allowing some air leakage to occur during firing.

The damage and effect of different fabrics was discussed in an earlier section but the trend can be seen numerically in tables 3 and 4 . The thicker yarn and tougher weave (rather than the loop stitch in the tee shirt) means there is more mutual support from other fibres when taking the strain and the stress is spread over a larger area. Only 4 out of 36 shots managed to penetrate the jacket in this test series and these were all at $9.1 \mathrm{~m}$ range. The jacket, like the jeans in series 1 , reduces or prevents penetration more noticeably than other fabrics.

The data for the tee-shirt and fleece in the second series is more complex to understand. There is a significant reduction in penetration in both cases with both, and figures $10 \mathrm{a}$ and $10 \mathrm{~b}$ show the trends of the means of 6 firings but because of the limited data points it is difficult to extrapolate or to interpolate. There appears to be an increasing effect of clothing at longer range i.e. the clothing is neither achieving a 
fixed reduction in penetration nor a constant percentage reduction in penetration. Indeed, at $18.3 \mathrm{~m}$ all three items prevented penetration in most cases (over $80 \%$ ). By way of contrast the unclothed gels in this series showed very little variation in penetration up to $18.3 \mathrm{~m}$ range. An explanation for this phenomenon is required.

One possible explanation for the observation of the pellets that did not penetrate may come by considering the impulse on impact. Wightman et al [3] have previously discussed how liquids can appear to behave as a solid, for example in stone skimming and Moy et al [20] have shown how ballistic gel behaves differently under different strain rates.

For the following calculations typical estimates are used to determine the magnitude of factors taking place on impact. The pellets were fired at $150 \mathrm{~ms}^{-1}$ and lost $5-15 \%$ of their penetration before impact with the gel. Penetration may depend linearly on energy (and hence velocity squared) or on momentum (linear with respect to velocity). From either calculation a reduction of $10 \%$ in velocity is therefore a reasonable estimate based on the reduced penetration observed from zero to $9.1 \mathrm{~m}$ (i.e. an estimated impact velocity of $135 \mathrm{~ms}^{-1}$ ).

If the pellet is stopped within $5 \mathrm{~mm}$ (the assumed depth of penetration in the depression in the fabric, although this was not measured at the time) it is possible to estimate the average retarding time:

(2) $t=2 s / v$ (derived from equations of motion and assuming a constant negative acceleration).

Substituting $5 \times 10^{-3} \mathrm{~m}$ and $135 \mathrm{~ms}^{-1}$ gives a stopping time of $7.4 \times 10^{-5}$ seconds. Impulse and momentum are related:

(3) $\quad$ F.t $=m \cdot v$

In order to bring the pellet momentum to zero from $0.122 \mathrm{~kg} \cdot \mathrm{m} \cdot \mathrm{s}^{-1}\left(0.9 \times 10^{-3} \mathrm{~kg}\right.$ at $135 \mathrm{~ms}^{-1}$ on impact) in $7.4 \times 10^{-5} \mathrm{~s}$ needs a force of $1700 \mathrm{~N}$. Assuming this force is applied at a constant rate during deceleration and is applied evenly over the cross sectional area of the pellet, this requires a stress of $100 \mathrm{MPa}$. This is well below the tensile strength of individual cotton fibres at $1000 \mathrm{MPa}$. [21] Fibres will not therefore 
break, although penetration could occur by cutting or moving yarn aside. The retarding force has to be provided by deformation of the yarn and the energy transmitted to the gel. This transmission of energy would account for the gel fracture tracks seen in figure $9 \mathrm{~b}$. This transmission of energy by the impulse on impact may contribute towards the increased damage in indirect ballistic fractures when clothing is present, as noted by Kieser et al [14].

Two observations remain unexplained. Firstly, although it has the least aerodynamic shape the hobby pellets suffered less reduction in penetration than superdome pellets when comparing clothed gels with unclothed gels. The opposite had been expected because of the greater drag resistance. One possible explanation may be the sharper edge and the pellet punching its way through the material similar to a paper hole punch but this does require further investigation. The second unexpected result was the apparent effectiveness at $18.3 \mathrm{~m}$ for loose clothing to stop penetration. This cannot simply be related to the lower velocity at the greater range as the penetration in unclothed gels was virtually unchanged. Again, further work is required to assess these observations. 


\section{Conclusion}

The firing of low power pellets from air rifles into clothing encasing ballistic gel has been investigated. Gels were tested by both Bloom and rupture tests and some variation was observed in the properties of gels from different sources. Measurement of physical properties of gels can be used as a pre-screening before firing tests are carried out. In several series of tests firing into different batches of 6 replicate gels the relative standard deviation of penetration was consistently below $10 \%$. The use of cinnamon oil was found to be an effective preservative and mechanical properties of the gel appeared unchanged over a two week period.

Intuitively it may be thought that clothing will provide a measure of protection with air air gun pellets but the reality is complex. Clothing in contact with the gel block reduced penetration but a much greater relative standard deviation was obtained for the penetration depth in replicate shootings into ballistic gel loosely surrounded by clothing. Clothing can induce tumbling although in many cases the pellet track and final pellet orientation did not suggest that tumbling had occurred and so the clothing appears to be providing a variable retardation to the pellet. Fibres were drawn into the gel wound even with low energy pellets, indicating the potential for foreign bodies and microorganism infecting the wound.

Damage to clothing depended on pellet shape and fabric weave. Woven material and coarser yarn had a greater stopping effect than loop stitching or narrower yarn. A fleece material of non-interlinked fibres was least effective in stopping the pellet. Damage was a mixture of pushing and cutting/tearing. When clothing prevented penetration (typically at $18.3 \mathrm{~m}$ range in this series of tests) there was evidence of damage to the underlying gel. It is suggested that impulse rather than energy or momentum may have a role to play and a preliminary estimate suggests a the pellet may be stopped in around 75 microseconds and require an average force of $1700 \mathrm{~N}$ or a stress of around $100 \mathrm{MPa}$.

The clothing produces a reduction in penetration with loosely held fibres having least effect and loop stitching less effect than woven material. Clothing in contact with gel resulted in some reduction in penetration but there is a greater reduction and 
variation in penetration with loosely held clothing. There is a trend and the depth of penetration depends on shooting range, with very few pellets penetrating at $18.3 \mathrm{~m}$ in this study. The nature of the correlation is unidentified and the dependency on range was much greater than for unclothed gels. Care therefore needs to be taken when assessing air weapon injuries in trying to evaluate the effect of clothing.

\section{Acknowledgements}

The authors gratefully acknowledge the assistance given by Tayside airgun club, and for the use of their range. The loan of a digital-optical microscope by Olympus and the use of the tensiometer from Food Innovation @ Abertay are also acknowledged. 


\section{References}

[1] A. Stankova, Z. Jakovskia, G. Pavlovskia, N. Muricd, A. J. Dworka, and Z. Cakara, Air gun injury with deadly aftermath - Case report, Legal Medicine 15 (2013) 35-37

[2] M.M. Al-Qattan, Air gun pellet injuries of the hand, Journal of Hand Surgery (British) 31 (2006) 178.

[3] G. Wightman, J. Beard, and R. Allison, R., An investigation into the behaviour of air rifle pellets in ballistic gel and their interaction with bone, Forensic Science International, 200 (2010) 41-49

[4] G. Wightman, R. Cochrane, R. A. Gray, and M. Linton, A contribution to the discussion on the safety of air weapons, Science and Justice 53 (2013) 343-349

[5] H-H Meng, P-C. Tsai, and Y-H. Chen, The effect of ambient temperature variation to the muzzle energy of airguns, Forensic Science Journal 2013;12(1):47-56

[6] R.M. Bruce-Chwatt, Air gun wounding and current UK laws controlling airweapons, Journal of Forensic and Legal Medicine 17 (3) (April 2010) 123-126.

[7] G.I. Ogunc, M. T. Ozer, M. Eryilmaz, O Karakus, and A. I. Uzar, The wounding potential and legal situations of air guns - experimental study, Australian Journal of Forensic Sciences, 2014 Vol. 46, No. 1, 39-52.

[8] B. J. Agrawal, High performance textiles for ballistic protection, Defense Science Research Conference and Expo (DSR), 2011 August 3-5, 1-4

[9] A. Aming, and R. Chitaree, Physical analysis of damaged tissue simulant covered by textiles made by sharp knife stabbing, Thai Journal of Physics 6 (2010) available on www.forensic.sc.mahidol.ac.th/proceeding/51 asmar.pdf

[10] G. Nolan, S. Hainsworth, and G. N. Rutty, Forces required for a knife to penetrate a variety of clothing types, J. Forensic Sci. 58.2 (March 2013) 372-379 [11] N. Johnson, Physical damage to textiles, Asia Pacific Police Technology Conference : proceedings of a conference held 12-14 November 1991 / edited by Julia Vernon and Des Berwick, available on http://www.aic.gov.au/media library/publications/proceedings/18/johnson.pdf 
[12] O. Heuse,1982, 'Damage to Clothing Caused by Stabbing Tools', Archiv fuer Kriminologie, vol. 170, pp. 129-45

[13] B. Venneman, F. Dautel, R. Braunwarth, E. Strassburger, M. Hunzinger, S. Pollak, and M. G. Perdekamp, Textile fibres along the bullet path - experimental study on a skin-gelatine composite model, Int. J. Legal Med. 122 (2008) 213-218 [14] D. C. Kieser, D. J. Carr, S. C. Leclair, I. Horsfall, J.-C. Theis, M. V. Swain, and J. A. Kieser, Clothing increases the risk of indirect ballistic fractures, Journal of Orthopaedic Surgery and Research 2013, 8:42

[15] J. Jussila, 2004. Preparing ballistic gelatine-review and proposal for a standard method. Forensic Science International. 141(2-3): pp. 91-98

[16] M. L. Fackler, and J. A. Malinowski, 1988. Ordnance gelatin for ballistic studies. Detrimental effect of excess heat used in gelatin preparation. The American Journal of Forensic Medicine and Pathology. 9(3):pp. 218-9.

[17] V.J.M. DiMaio, A.R. Copeland, P.E. Besant-Matthews, L.A. Flectcher, and A. Jones, Minimal velocities necessary for perforation of skin by air gun pellets and bullets, Journal of Forensic Sciences, JFSCA 27 (4) (Oct. 1982) 894-898.

[18] N.A.S.A., Shape effects on drag, available on http://www.grc.nasa.gov/WWW/k12/airplane/shaped.htm

[19] J. Jussila, Measurement of kinetic energy dissipation with gelatine fissure formation with special reference to gelatine validation, Forensic Science International 150 (2005) 53-62

[20] P. Moy, T. Weerasooriya, and C. A. Gunnarsson, Tensile Deformation of Ballistic Gelatin as a Function of Loading Rate, Proceedings of the XIth International Congress and Exposition June 2-5, 2008 Orlando, Florida USA, Society for Experimental Mechanics Inc.

[21] S. Basu, Tensile deformation of fibres used in textile industry, available on http://cp.literature.agilent.com/litweb/pdf/5991-0274EN.pdf) 
Figure 1: Bloom strength test on two gel types: a) Gelita, and b) Fluka
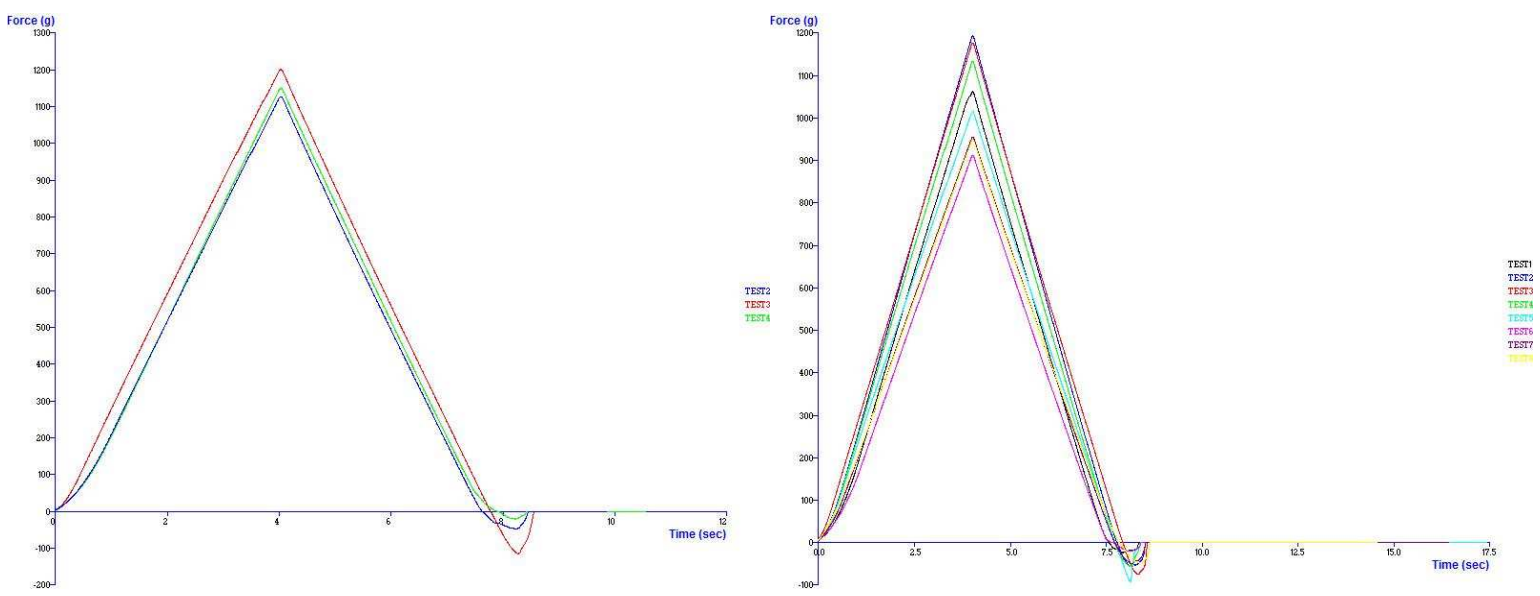
Figure 2: Rupture test on two gel types: a) Gelita, and b) Fluka
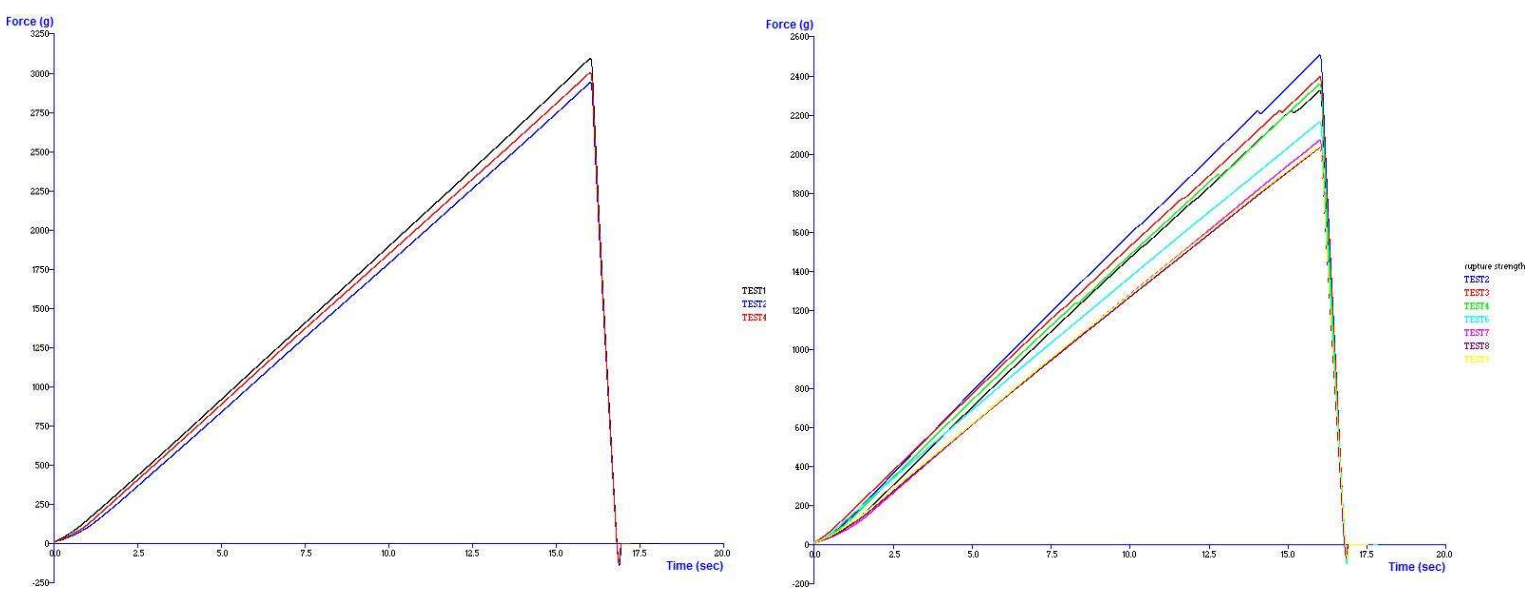
Figure 3: Rupture test on preserved gel after a) 1 day, and b) 14 days.
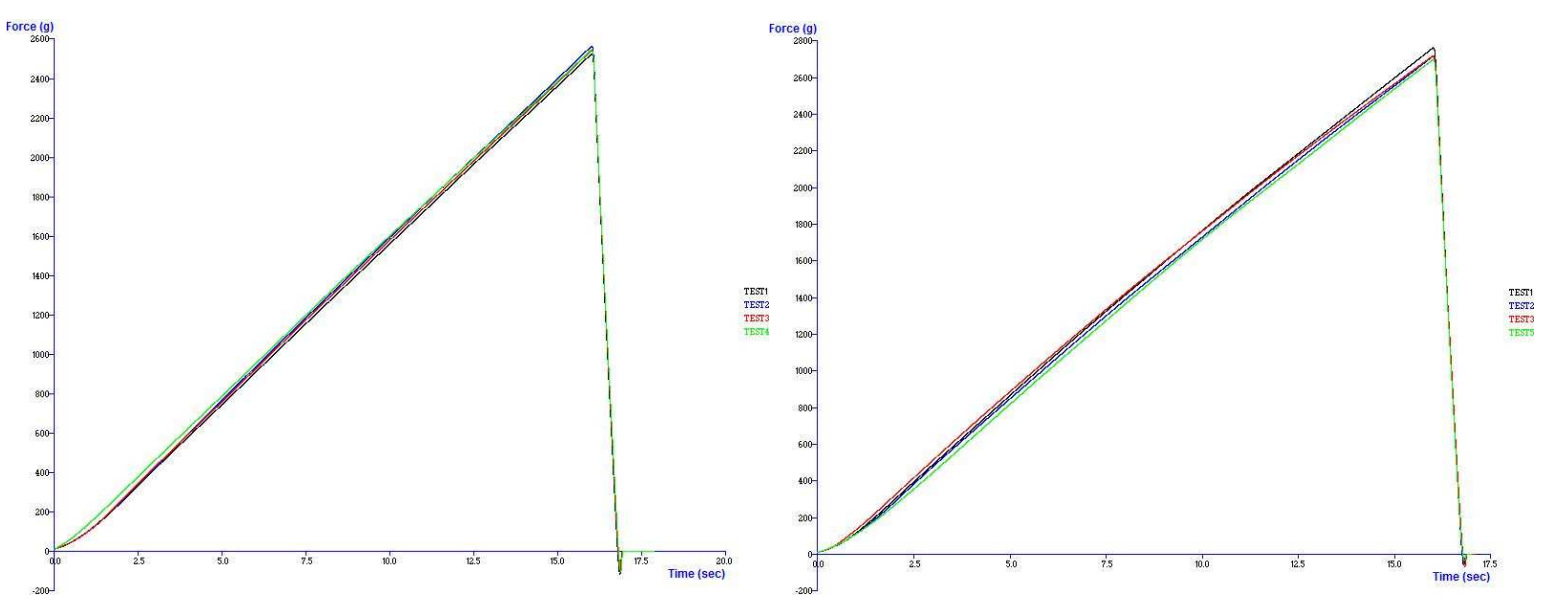
Figure 4: White growth in ballistic gel after firing

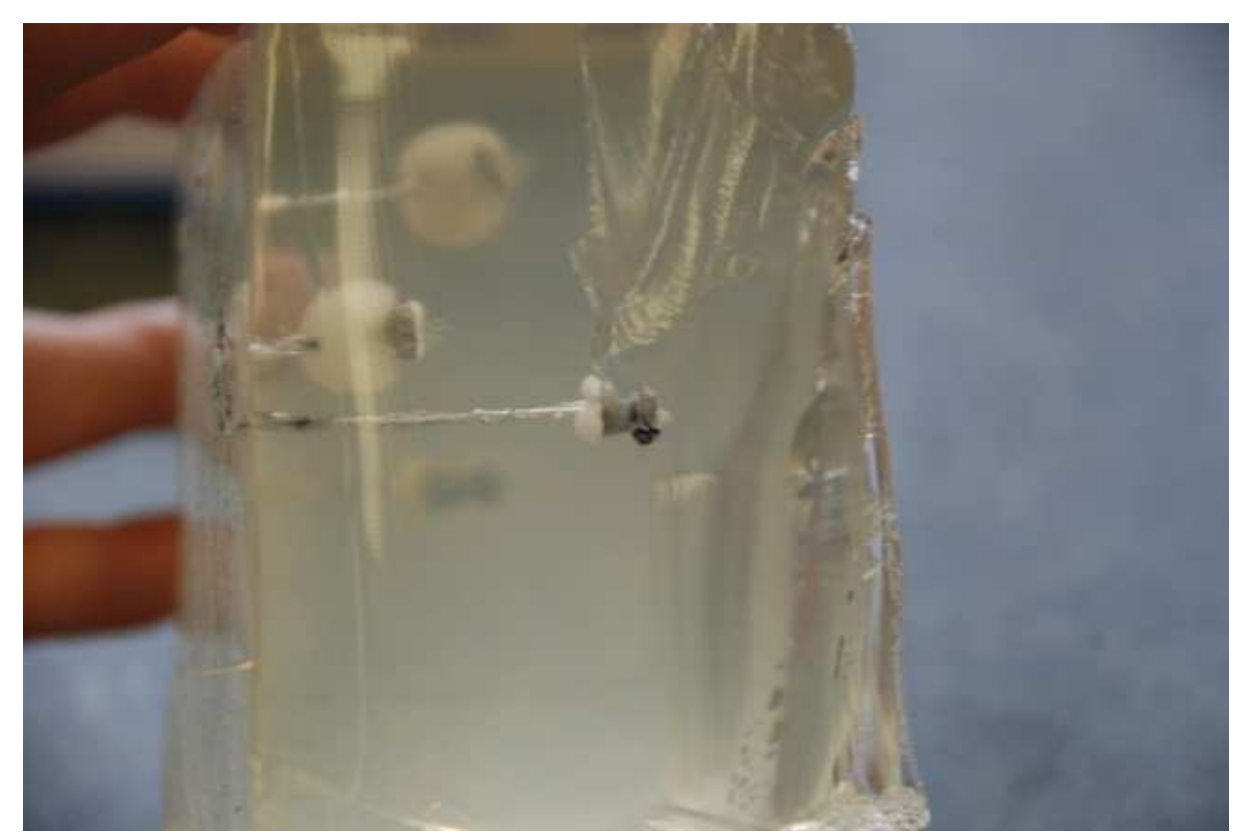


Figure 5: Entrainment of fibres when shooting through clothing a) entainment on pellet, and b) entrainment in gel

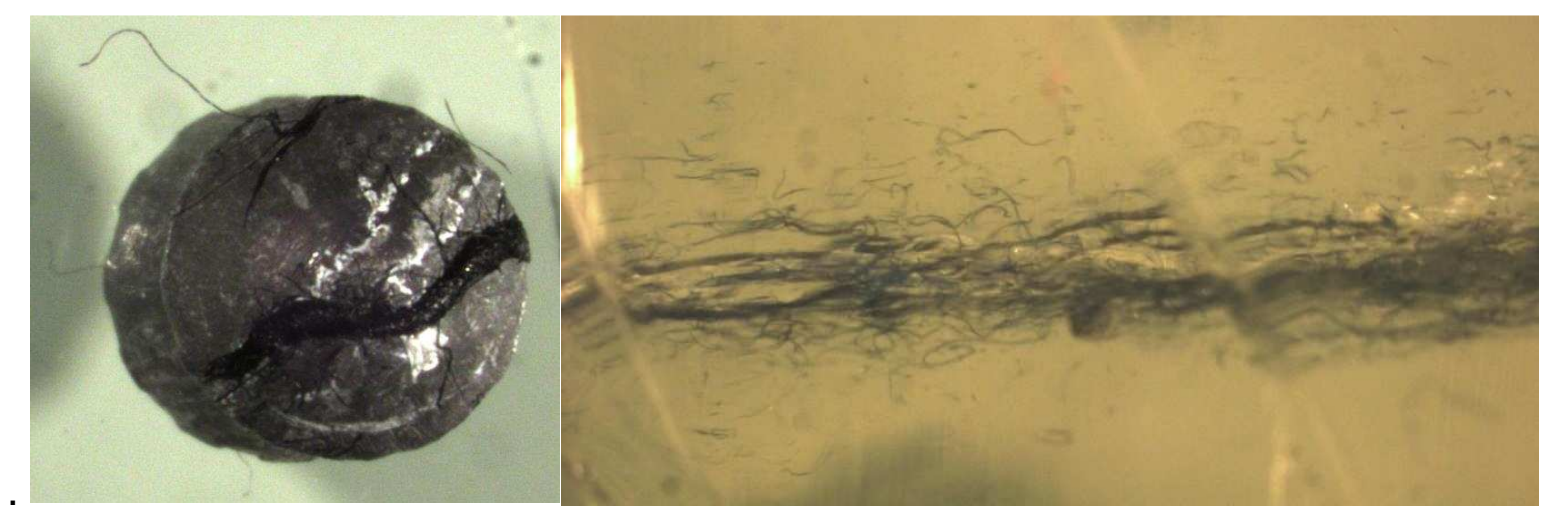


Figure 6: Pellet shapes
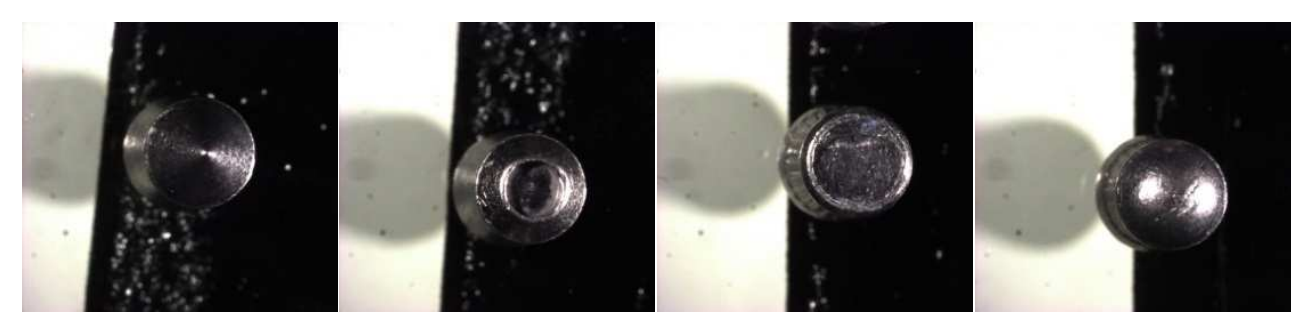

Pointed Hollow point

Flat (Hobby) Round (Superdome) 
Figure 7: Typical damage on tee shirt and jeans caused by 4 pellet types (series 1).

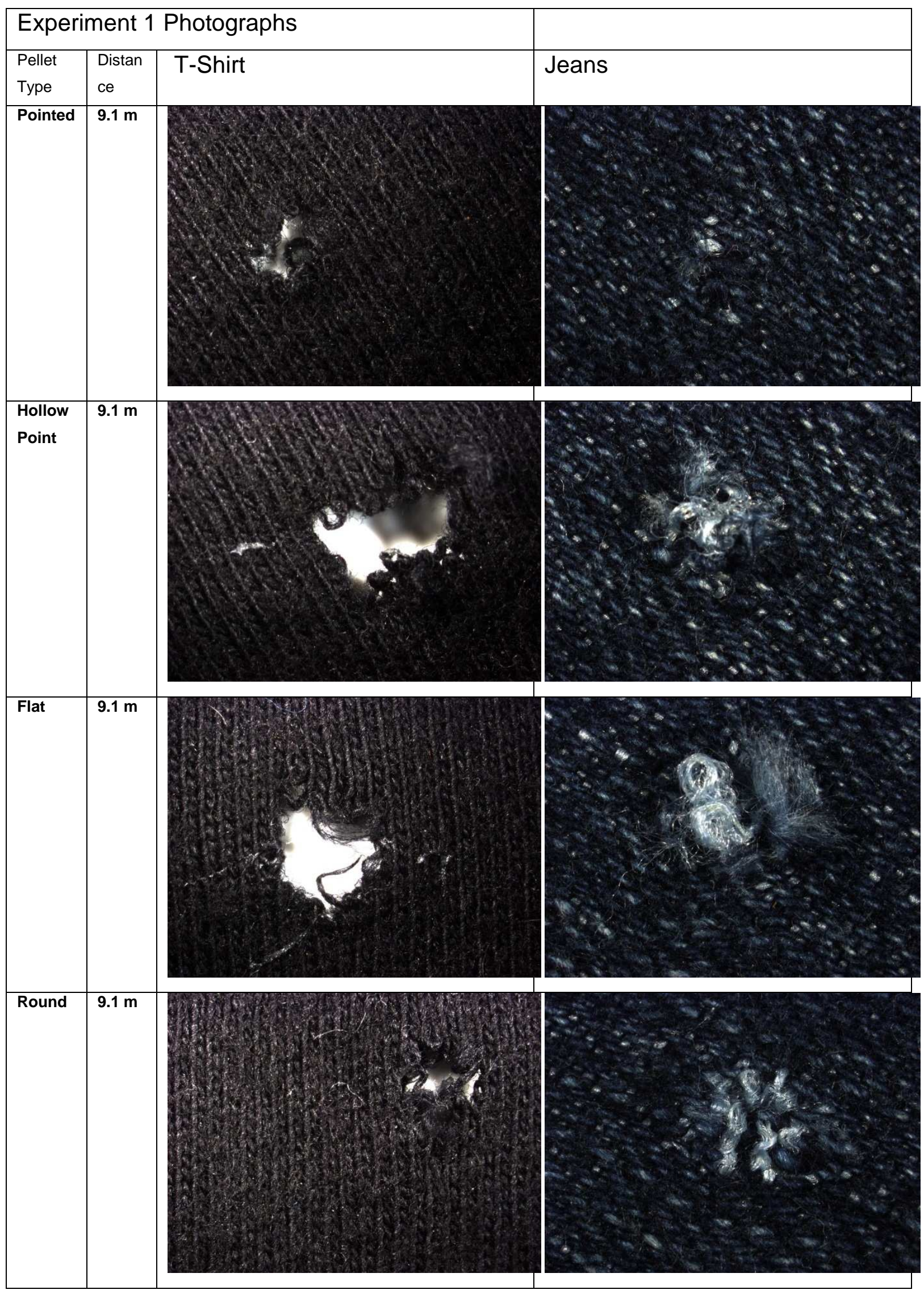


Figure 8: Damage caused by two pellet types on tee shirt, fleece and jacket (series 2).

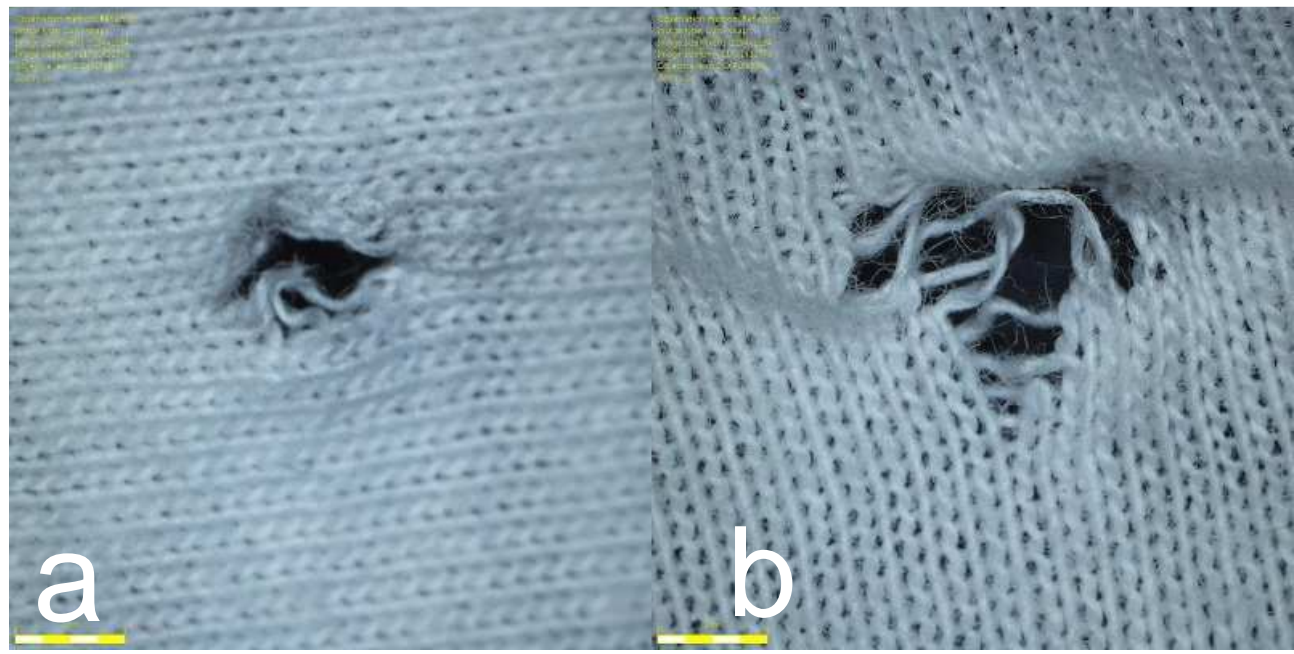

Damage caused by (a) superdome pellet and (b) hobby pellet to the t-shirt at $9.1 \mathrm{~m}$.

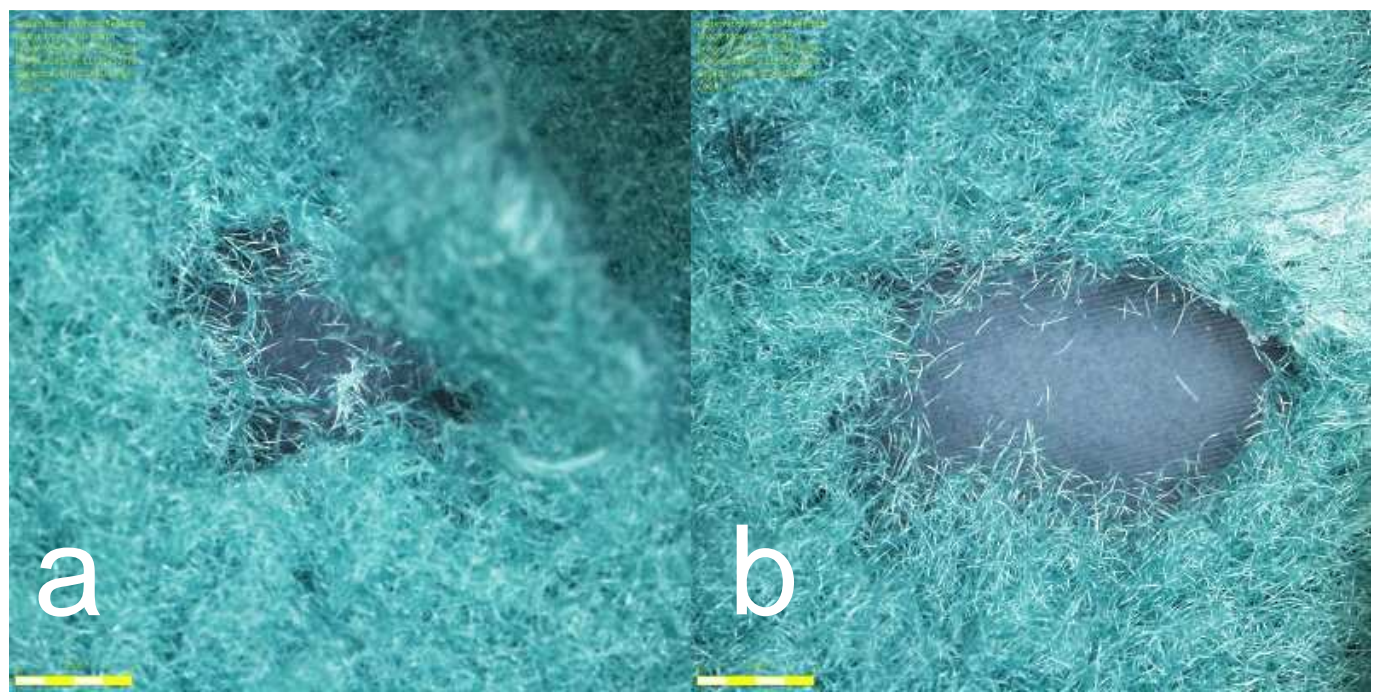

Damage caused by (a) superdome pellet and (b) hobby pellet to the fleece at $9.1 \mathrm{~m}$.

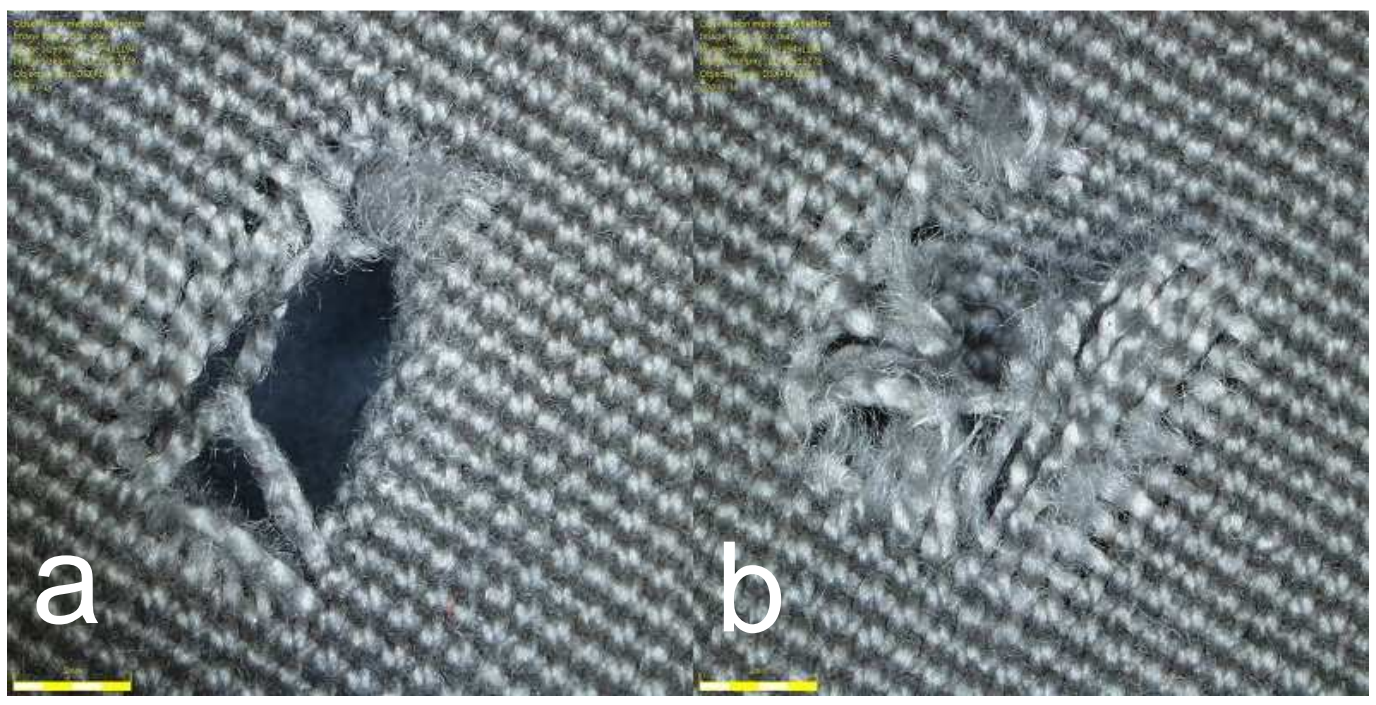

Damage caused by (a) superdome pellet and (b) hobby pellet to the jacket at $9.1 \mathrm{~m}$. 
Figure 9: Damage caused by non-penetrating pellets (series 2)

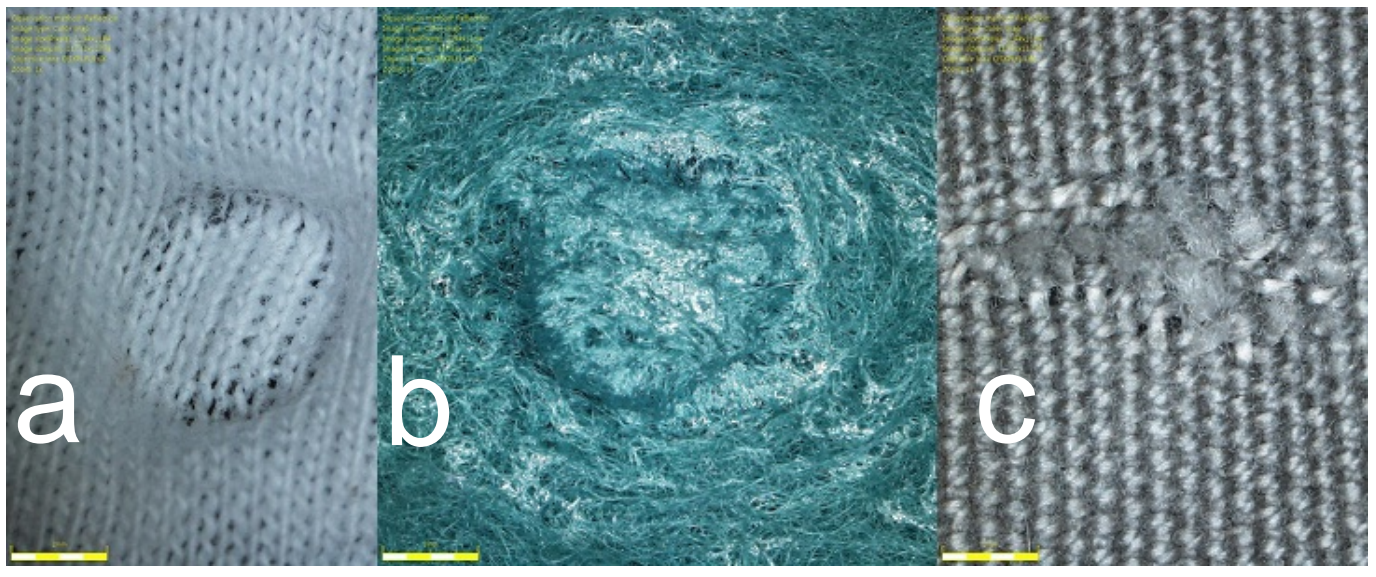

Non-penetrating damage visible on the (a) t-shirt, (b) fleece and (c) jacket.

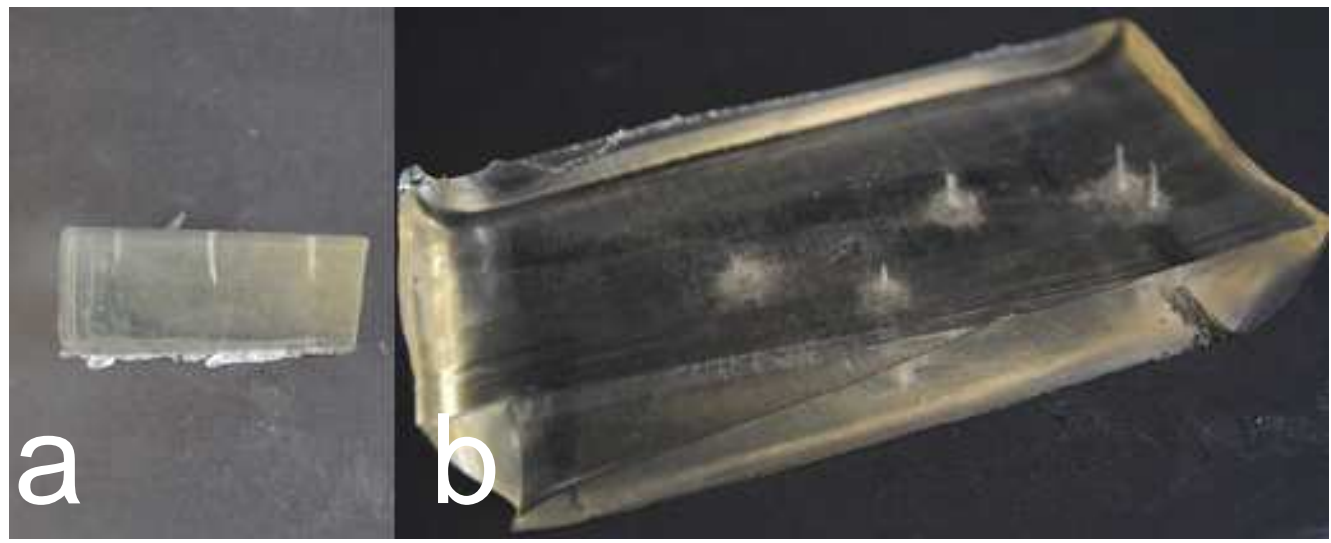

Non-penetrating damage visible in sections of gelatine with (a) hobby pellets and (b) superdome pellets. 
Table 1: Air weapon and pellet combinations used:

\section{Series 1}

Weapon

Pellet

RWS

Hobby

Pellet shape

Muzzle

energy $\mathrm{J}$

Muzzle

velocity $\mathrm{ms}$
.177

.177 Airarms S200 Air Rifle

Flat

14.2

250

Round

Hollow Point

14.7

14.7

234

235

$\begin{array}{rrr}.177 \text { RWS } & .177 \text { RWS } & .177 \text { RWS Super } \\ \text { Superdome } & \text { Super H } & \text { Point Extra }\end{array}$

Series 2

Sportsmarketing SYNXS

.22 air rifle

RWS RWS

Superdome Hobby

pellets

Pointed Round Flat

14

11

10.9

249

153

166 
Table 2: Effect of loading pellets backwards at zero range

\begin{tabular}{|c|c|c|c|c|}
\hline & & Penet & $\mathrm{n} / \mathrm{cm}$ & \\
\hline & $\begin{array}{r}\text { Superdome } \\
\text { loaded } \\
\text { normally } \\
14.20\end{array}$ & $\begin{array}{r}\text { Hobby } \\
\text { loaded } \\
\text { normally } \\
11.40\end{array}$ & $\begin{array}{r}\text { Superdome } \\
\text { loaded } \\
\text { backwards } \\
8.60\end{array}$ & $\begin{array}{r}\text { Hobby } \\
\text { loaded } \\
\text { backwards } \\
6.40\end{array}$ \\
\hline & 13.50 & 12.00 & 8.90 & 6.40 \\
\hline & 12.00 & 10.40 & 8.50 & 5.80 \\
\hline & 12.10 & 10.00 & 7.50 & 5.60 \\
\hline & 12.00 & 10.00 & & \\
\hline & 12.30 & 10.10 & & \\
\hline Mean & 12.68 & 10.65 & 8.38 & 6.05 \\
\hline $\begin{array}{l}\text { Standard } \\
\text { deviation }\end{array}$ & 0.94 & 0.85 & 0.61 & 0.41 \\
\hline Backwards/normal & & & $66.03 \%$ & $56.81 \%$ \\
\hline
\end{tabular}


Table 3: Penetration of pellets into gel with clothing, series 1.

\begin{tabular}{|c|c|c|c|c|c|c|c|c|c|c|c|c|c|}
\hline & & \multicolumn{8}{|c|}{ Distance Travelled cm } & \multicolumn{4}{|c|}{$\begin{array}{l}\text { Percentage pellet penetration compared } \\
\text { with round pellet }\end{array}$} \\
\hline \multicolumn{2}{|l|}{ Clothing } & \multicolumn{4}{|c|}{ Tee-shirt } & \multicolumn{4}{|c|}{ Jeans } & \multicolumn{2}{|c|}{ Tee-shirt } & \multicolumn{2}{|c|}{ Jeans } \\
\hline & & Cotton & $\begin{array}{r}\text { Cotton } \\
\text { polyester }\end{array}$ & Mean & RSD & $\begin{array}{r}75 \% \\
\text { cotton }\end{array}$ & $\begin{array}{r}98 \% \\
\text { cotton }\end{array}$ & Mean & RSD & Cotton & $\begin{array}{r}\text { Cotton } \\
\text { polyester }\end{array}$ & $\begin{array}{r}75 \% \\
\text { cotton }\end{array}$ & $\begin{array}{r}98 \% \\
\text { cotton }\end{array}$ \\
\hline Pointed & Range & 12.9 & 13.0 & 13.0 & $0.5 \%$ & 13.4 & 13.7 & 13.6 & $1.6 \%$ & $88 \%$ & $81 \%$ & $88 \%$ & $91 \%$ \\
\hline Round & $9.1 \mathrm{~m}$ & 14.6 & 16.0 & 15.3 & $6.5 \%$ & 15.3 & 15.0 & 15.2 & $1.4 \%$ & $100 \%$ & $100 \%$ & $100 \%$ & $100 \%$ \\
\hline Flat & & 7.0 & 8.5 & 7.8 & $13.7 \%$ & 8.6 & 8.5 & 8.6 & $0.8 \%$ & $48 \%$ & $53 \%$ & $56 \%$ & $57 \%$ \\
\hline $\begin{array}{r}\text { Hollow } \\
\text { Point }\end{array}$ & & 7.5 & 9.0 & 8.3 & $12.9 \%$ & 9.6 & 9.5 & 9.6 & $0.7 \%$ & $51 \%$ & $56 \%$ & $63 \%$ & $63 \%$ \\
\hline Pointed & Range & 12.3 & 12.8 & 12.6 & $2.8 \%$ & 11.3 & 13.0 & 12.2 & $9.9 \%$ & $93 \%$ & $86 \%$ & & $100 \%$ \\
\hline Round & $18.3 \mathrm{~m}$ & 13.2 & 14.8 & 14.0 & $8.1 \%$ & 6.2 & 13.0 & 9.6 & $50.1 \%$ & $100 \%$ & $100 \%$ & & $100 \%$ \\
\hline Flat & & 7.3 & 7.8 & 7.6 & $4.7 \%$ & 5.0 & 6.8 & 5.9 & $21.6 \%$ & $55 \%$ & $53 \%$ & & $52 \%$ \\
\hline $\begin{array}{r}\text { Hollow } \\
\text { Point }\end{array}$ & & 8.1 & 8.8 & 8.5 & $5.9 \%$ & 7.7 & 8.5 & 8.1 & $7.0 \%$ & $61 \%$ & $59 \%$ & & $65 \%$ \\
\hline Pointed & Range & 10.3 & 11.0 & 10.7 & $4.6 \%$ & 8.5 & 10.4 & 9.5 & $14.2 \%$ & $86 \%$ & $79 \%$ & $77 \%$ & $83 \%$ \\
\hline Round & $27.4 \mathrm{~m}$ & 12.0 & 14.0 & 13.0 & $10.9 \%$ & 11.1 & 12.5 & 11.8 & $8.4 \%$ & $100 \%$ & $100 \%$ & $100 \%$ & $100 \%$ \\
\hline Flat & & 6.8 & 7.8 & 7.3 & $9.7 \%$ & 6.5 & 6.0 & 6.3 & $5.7 \%$ & $57 \%$ & $56 \%$ & $59 \%$ & $48 \%$ \\
\hline $\begin{array}{r}\text { Hollow } \\
\text { Point } \\
\end{array}$ & & 7.1 & 9.0 & 8.1 & $16.7 \%$ & 2.3 & 6.9 & 4.6 & $70.7 \%$ & $59 \%$ & $64 \%$ & $21 \%$ & $55 \%$ \\
\hline
\end{tabular}

Tee shirts are $100 \%$ cotton or $60 \%$ cotton $40 \%$ polyester

Jeans are $75 \%$ cotton $23 \%$ polyester $2 \%$ elastane or $98 \%$ cotton $2 \%$ elastane 
Table 4: Penetration of pellets into gel with and without clothing, series 2.

\begin{tabular}{lrrr} 
& \multicolumn{3}{c}{ Superdome } \\
& $\mathbf{9 . 1}$ & $\mathbf{1 3 . 7}$ & $\mathbf{1 8 . 3}$ \\
& 12.5 & 11.4 & 11.9 \\
& 12.0 & 12.3 & 11.2 \\
& 12.9 & 10.8 & 11.1 \\
& 11.8 & 11.4 & 11.0 \\
& 10.5 & 11.4 & 11.2 \\
& 11.5 & 11.2 & 10.6 \\
Mean excluding outliers & 11.87 & 11.42 & 11.17 \\
Standard deviation & 0.84 & 0.49 & 0.42 \\
RSD & $7.0 \%$ & $4.3 \%$ & $3.8 \%$ \\
& & Hobby & \\
& $\mathbf{9 . 1}$ & $\mathbf{1 3 . 7}$ & $\mathbf{1 8 . 3}$ \\
& 8.5 & 9.5 & 9.1 \\
& 10.2 & 10.4 & 10.0 \\
& 5.0 & 9.9 & 10.0 \\
& 9.5 & 8.9 & 8.1 \\
& 9.5 & 9.2 & 9.0 \\
Mean excluding outliers & 8.8 & 8.7 & 8.1 \\
Standard deviation & 9.30 & 9.43 & 9.05 \\
RSD & 0.67 & 0.64 & 0.85 \\
Hobby/Superdome & $7.2 \%$ & $6.8 \%$ & $9.4 \%$ \\
Superdome/Superdome 9.1 m & & & \\
Hobby/Hobby 9.1 m & $100.0 \%$ & $96.2 \%$ & $94.1 \%$ \\
Superdome/gel no clothing & $100.0 \%$ & $101.4 \%$ & $97.3 \%$ \\
Hobby/gel no clothing & $100.0 \%$ & $100.0 \%$ & $100.0 \%$ \\
& $100.0 \%$ & $100.0 \%$ & $100.0 \%$
\end{tabular}

\begin{tabular}{rrr}
\multicolumn{3}{c}{ Superdome tee shirt } \\
$\mathbf{9 . 1}$ & $\mathbf{1 3 . 7}$ & $\mathbf{1 8 . 3}$ \\
8.2 & 4.2 & 0.4 \\
6.0 & 5.5 & 5.5 \\
3.7 & 2.7 & 0.0 \\
2.6 & 2.2 & 0.0 \\
9.4 & 5.0 & 0.0 \\
5.0 & 0.0 & 0.0 \\
5.82 & 3.92 & 0.00 \\
2.61 & 1.43 & 0.00 \\
$44.9 \%$ & $36.5 \%$ &
\end{tabular}

Hobby tee shirt

$\begin{array}{lll}9.1 & 13.7 & 18.3\end{array}$

$\begin{array}{lll}4.1 & 2.0 & 0.0\end{array}$

$\begin{array}{lll}2.5 & 2.2 & 0.0\end{array}$

$\begin{array}{lll}8.0 & 2.3 & 0.0\end{array}$

$\begin{array}{lll}0.0 & 0.0 & 0.0\end{array}$

$\begin{array}{lll}3.9 & 2.0 & 1.8\end{array}$

$\begin{array}{lll}6.5 & 1.9 & 0.0\end{array}$

$\begin{array}{lll}5.00 & 2.08 & 0.00\end{array}$

$\begin{array}{lll}2.21 & 0.16 & 0.00\end{array}$

$44.2 \% \quad 7.9 \%$

$86.0 \% \quad 53.1 \%$

$100.0 \% \quad 67.4 \% \quad 0.0 \%$

$100.0 \% \quad 41.6 \% \quad 0.0 \%$

$49.0 \% \quad 34.3 \% \quad 0.0 \%$

$53.8 \% \quad 22.0 \% \quad 0.0 \%$

\section{Superdome fleece}

$\begin{array}{lll}9.1 & 13.7 & 18.3\end{array}$

$\begin{array}{lll}9.2 & 6.5 & 0.0\end{array}$

$\begin{array}{lll}8.4 & 7.0 & 2.5\end{array}$

$\begin{array}{lll}6.9 & 0.0 & 0.0\end{array}$

$\begin{array}{lll}6.7 & 5.9 & 0.0\end{array}$

$\begin{array}{lll}5.1 & 4.5 & 0.0\end{array}$

$\begin{array}{lll}8.0 & 4.9 & 0.0\end{array}$

$\begin{array}{lll}7.38 & 5.76 & 0.00\end{array}$

$\begin{array}{lll}1.46 & 1.05 & 0.00\end{array}$

$19.7 \% \quad 18.3 \%$

\section{Hobby fleece}

$\begin{array}{lll}9.1 & 13.7 & 18.3\end{array}$

$\begin{array}{lll}6.2 & 5.5 & 0.0\end{array}$

$\begin{array}{lll}7.8 & 5.2 & 1.9\end{array}$

$\begin{array}{lll}5.1 & 5.0 & 4.5\end{array}$

$\begin{array}{lll}7.9 & 1.2 & 0.0\end{array}$

$\begin{array}{lll}6.0 & 4.8 & 1.3\end{array}$

$\begin{array}{lll}5.3 & 4.1 & 0.0\end{array}$

$\begin{array}{lll}6.38 & 4.92 & 1.28\end{array}$

$\begin{array}{lll}1.21 & 0.53 & 1.77\end{array}$

$18.9 \% \quad 10.7 \%$

$86.5 \% \quad 85.4 \%$

$100.0 \% \quad 78.0 \% \quad 0.0 \%$

$100.0 \% \quad 77.1 \% \quad 20.1 \%$

$62.2 \% \quad 50.5 \% \quad 0.0 \%$

$68.6 \% \quad 52.2 \% \quad 14.2 \%$
Superdome jacket

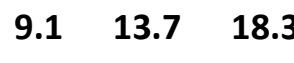

$\begin{array}{lll}2.9 & 0.0 \quad 0.0\end{array}$

$\begin{array}{lll}3.0 & 0.0 & 0.0\end{array}$

$\begin{array}{lll}0.0 & 0.0 & 0.0\end{array}$

$\begin{array}{lll}0.0 & 0.0 & 0.0\end{array}$

$\begin{array}{lll}0.0 & 0.0 & 0.0\end{array}$

$\begin{array}{lll}0.0 & 0.0 & 0.0\end{array}$

$\begin{array}{lll}0.00 & 0.00 & 0.00\end{array}$

$\begin{array}{lll}0.00 & 0.00 & 0.00\end{array}$

\section{Hobby jacket}

$\begin{array}{lll}9.1 & 13.7 \quad 18.3\end{array}$

$\begin{array}{lll}0.0 & 0.0 & 0.0\end{array}$

$\begin{array}{lll}0.0 & 0.0 & 0.0\end{array}$

$\begin{array}{lll}0.0 & 0.0 & 0.0\end{array}$

$\begin{array}{lll}0.0 & 0.0 & 0.0\end{array}$

$\begin{array}{lll}1.2 & 0.0 & 0.0\end{array}$

$\begin{array}{lll}1.0 & 0.0 & 0.0\end{array}$

$\begin{array}{lll}0.00 & 0.00 & 0.00\end{array}$

$\begin{array}{lll}0.00 & 0.00 & 0.00\end{array}$

Penetration in $\mathrm{mm}$. ratios in percent. 